\title{
Gas-Phase Reactions in the ISM: Rate Coefficients, Temperature Dependences, and Reaction Products
}

\author{
Ian W. M. Smith \\ Department of Chemistry \\ University of Cambridge \\ Lensfeld Road \\ Cambridge CB2 1EW, UK
}

\begin{abstract}
Information about the rate coefficients and products of processes that occur in the interstellar medium are required as input to computer models that seek to reproduce the abundances of the rich variety of molecules that have been observed in different regions of the interstellar medium. In this brief review, I seek to identify the different kinds of gas-phase processes for which information is required and to consider the experimental, theoretical, and semi-empirical methods which are employed to measure or predict rate coefficients, $k(T)$, and how they depend on temperature $(T)$ - and also how the products of reactions can, in favourable cases, be observed.
\end{abstract}

\section{Introduction}

This is the third time that I have been asked to review aspects of chemical reaction kinetics before an audience of astronomers and astrochemists. On both previous occasions (Smith 1988; Smith 1997), my brief was to consider reactions between electrically neutral species, with some special emphasis on these reactions at low temperatures. This time, I have been asked to cast my net wider: to consider kinetics between a wider range of types of species and over a wider range of temperature. Given the time and space available, I could only cover the complete ranges of species and temperature by being extremely superficial. To avoid that, I shall be selective, but I start by summarising in Table 1 the range of gas-phase processes which play a role in the chemistry of the interstellar medium (ISM), giving examples of each type. In the last column of this Table, I give the number of examples of each kind of process that is included in one of the main kinetic data bases for astrochemistry - that maintained by Eric Herbst's group (http://physics.ohio-state.edu/ eric/research.html)

In this review, I shall concentrate on (i) ion-neutral reactions, and (ii) neutral-neutral reactions. More detailed discussions, how kinetic information is obtained for these kinds of reactions, and information about the other processes listed in Table 1 can be found in two recent publications (Wakelam et al. 2010a; Smith 2011).

The primary information for any reaction that might play a role in the chemistry of the ISM is of two kinds. First, there is the rate coefficient, $k(T)$, and how it depends on temperature $(T)$. The great majority of relevant processes are second-order: that is their rate is proportional to the product of the concentrations of two reactant species, say A and $\mathrm{B}$, so that the change in concentration of each as a result of their reaction can be written as: 
Table 1. Gas-phase reactions of different types included in the OSU database (version osu-09-2008) for astrochemistry.

\begin{tabular}{|c|c|c|}
\hline Type of process & Example & $\begin{array}{l}\text { Number } \\
\text { in model }\end{array}$ \\
\hline Gas-grain interactions & $\mid \mathrm{H}+\mathrm{H}+$ grain $\rightarrow \mathrm{H}_{2}+$ grain $\mid$ & 14 \\
\hline Direct cosmic ray processes & $\mathrm{H}_{2}+\zeta \rightarrow \mathrm{H}_{2}^{+}+e$ & 11 \\
\hline Cation-neutral reactions & $\mathrm{H}_{2}^{+}+\mathrm{H}_{2} \rightarrow \mathrm{H}_{3}^{+}+\mathrm{H}$ & 2933 \\
\hline Anion-neutral reactions & $\mathrm{C}^{-}+\mathrm{NO} \rightarrow \mathrm{CN}^{-}+\mathrm{O}$ & 11 \\
\hline Radiative associations (ion) & $\mathrm{C}^{+}+\mathrm{H}_{2} \rightarrow \mathrm{CH}_{2}^{+}+h \nu$ & 81 \\
\hline Associative detachment & $\mathrm{C}^{-}+\mathrm{H}_{2} \rightarrow \mathrm{CH}_{2}+e$ & 46 \\
\hline Chemi-ionization & $\mathrm{O}+\mathrm{CH} \rightarrow \mathrm{HCO}^{+}+e$ & 1 \\
\hline Neutral-neutral reactions & $\mathrm{C}+\mathrm{C}_{2} \mathrm{H}_{2} \rightarrow \mathrm{C}_{3} \mathrm{H}+\mathrm{H}$ & 382 \\
\hline Radiative association (neutral) & $\mathrm{C}+\mathrm{H}_{2} \rightarrow \mathrm{CH}_{2}+h \nu$ & 16 \\
\hline Dissociative recombination & $\mathrm{N}_{2} \mathrm{H}^{+}+e \rightarrow \mathrm{N}_{2}+\mathrm{H}$ & 539 \\
\hline Radiative recombination & $\mathrm{H}_{2} \mathrm{CO}^{+}+e \rightarrow \mathrm{H}_{2} \mathrm{CO}+h \nu$ & 16 \\
\hline Anion-cation recombination & $\mathrm{HCO}^{+}+\mathrm{H}^{-} \rightarrow \mathrm{H}_{2}+\mathrm{CO}$ & 36 \\
\hline Electron attachment & $\mathrm{C}_{6} \mathrm{H}+e \rightarrow \mathrm{C}_{6} \mathrm{H}^{-}+h \nu$ & 4 \\
\hline External photo-processes $^{a}$ & $\mathrm{C}_{3} \mathrm{~N}+h \nu \rightarrow \mathrm{C}_{2}+\mathrm{CN}$ & 175 \\
\hline Internal photo-processes $^{a}$ & $\mathrm{CO}+h \nu \rightarrow \mathrm{C}+\mathrm{O}$ & 192 \\
\hline
\end{tabular}

Notes: ${ }^{a}$ External photo-processes are those induced by the 'interstellar radiation field'; internal photo-processes are induced by radiation generated in dark clouds by the interaction of molecules, especially $\mathrm{H}_{2}$, with cosmic rays.

$$
-d[A] / d t=-d[B] / d t=k(T)[A][B]
$$

In the laboratory, $k(T)$ is usually determined by observing changes in the concentration of one reactant, say $\mathrm{A}$, in a large excess of the second reactant, $\mathrm{B}$, so that

$$
[A]_{t}=[A]_{0} \exp \left(-k_{1 s t} t\right) \text { where } k_{1 s t}=k(T)[B]
$$

In a series of experiments, $[B]$ is systematically varied and $k(T)$ is obtained from the variation of $k_{1 s t}$ with $[B]$. In data bases for interstellar chemistry (and elsewhere), the temperature-dependence of rate constants is frequently expressed using a modified form of the celebrated Arrhenius equation:

$$
k(T)=\alpha(T / 300)^{\beta} \exp (-\gamma / T)
$$

However, for only very few reactions, is the kinetic information sufficiently accurate over a wide enough range of temperatures for the parameters, $\alpha, \beta$ and $\gamma$, to be cited with much confidence.

The other piece of information that is required for each reaction is the nature of the products. Sometimes they can be inferred from thermodynamic arguments. Where this is not the case and more than one set of products is energetically accessible, the experimental determination of the branching ratios into different channels can be demanding. 
Table 2. Methods used to study the kinetics of ion-neutral reactions with the ranges of temeperatures over which experiments have been performed

\begin{tabular}{|l|c|c|}
\hline Method & Range T/K & Reference \\
\hline $\begin{array}{l}\text { ICR - ion } \\
\text { cyclotron resonance }\end{array}$ & 300 & Anicich (1993a), Anicich (1993b) \\
\hline $\begin{array}{l}\text { FA - flowing } \\
\text { afterglow }\end{array}$ & $82-600$ & Durkin et al. (1968), Ferguson et al. (1969) \\
\hline $\begin{array}{l}\text { SIFT - selected } \\
\text { ion flow tube }\end{array}$ & $\begin{array}{c}80-480 \\
18-295 \\
\text { up to 1400 }\end{array}$ & $\begin{array}{c}\text { Herbst et al. } \text { (1987), McIntosh, Adams, \& Smith (1988) } \\
\text { Bohringer, \& Arnold (1986) } \\
\text { Viggiano (2006) }\end{array}$ \\
\hline $\begin{array}{l}\text { SIFDT - selected } \\
\text { ion flow/drift tube }\end{array}$ & $\begin{array}{c}\text { kinectic energies } \\
\text { equivalent to } \\
1800 \mathrm{~K}\end{array}$ & Viggiano (2006) \\
\hline $\begin{array}{l}\text { CRESU - reaction } \\
\text { kinetics in uniform } \\
\text { supersonic flows }\end{array}$ & $8-300$ & Rowe et al. (1984), Rowe et al. (1985) \\
\hline
\end{tabular}

\section{Ion-Neutral Reactions}

As has been recognised for many years (e.g., Herbst \& Klemperer 1973), reactions between ions, especially cations, and neutral atoms and molecules are of primary importance in the ISM, especially in the cold cores of dark, dense clouds. The data base of rate coefficients for such reactions is extensive (e.g., Anicich 1993a,b; Snow \& Bierbaum 2008). The experimental techniques employed to obtain these data can be divided into two main categories (i) those in which the ionic reactant is trapped and then the rate of its loss observed as a neutral co-reactant is introduced; and (ii) those in which the ionic reactant is injected into a flowing gas and the loss of the ion is observed at a point downstream as a neutral reactant is added to the gas flow. In trapping experiments, it is necessary to work at low total gas density $\left(c a .10^{11} \mathrm{~cm}^{-3}\right)$, whereas flow experiments are conducted in excess helium at a density of $c a \cdot 10^{16} \mathrm{~cm}^{-3}$. In Table $2 \mathrm{I}$ list the variants of these methods and the temperature range over which they have been employed to provide rate coefficients for ion-neutral reactions.

Ion cyclotron resonance (ICR) experiments provided many of the early rate data on ion-neutral reactions but were limited to room temperature (Anicich 1993a,b). Later experiments using ion traps enabled measurements at temperatures as low as $10 \mathrm{~K}$ and are reviewed by Dunn (1995) and Gerlich (2008). These experiments have been especially useful in providing rate coefficients for important radiative association processes such as:

$$
\mathrm{C}^{+}+\mathrm{H}_{2} \rightarrow \mathrm{CH}_{2}^{+}+h \nu \quad \text { and } \quad \mathrm{CH}_{3}^{+}+\mathrm{H}_{2} \rightarrow \mathrm{CH}_{5}^{+}+h \nu \quad(\mathrm{R} 1 \mathrm{a}),(\mathrm{R} 1 \mathrm{~b})
$$

Several important developments in the deployment of flow methods should be noted.

- First was the development of the selected ion flow tube (SIFT) by Adams \& Smith (1976). In this technique, ions are created upstream of the main flow tube and then the desired ion is selected by a quadrupole mass filter before injection into the main gas flow. The SIFT method has been adapted to study (a) the kinetics of anion-neutral reactions (see Bierbaum elsewhere in these Proceedings), and (b) the reactions of ions with atomic radicals, such as H, N and O atoms (Snow \& Bierbaum 2008). Early SIFT experiments covered the temperature range 80-480 K (Herbst et al. 1987; McIntosh et al. 1988). In one heroic experiment, a SIFT apparatus was cooled using liquid He to reach 
18 K (Bohringer \& Arnold 1986), and, at the Air Force Research Laboratories, SIFT experiments have been performed at temperatures as high as $1400 \mathrm{~K}$ (Viggiano 2006).

- Second was the addition of an electric field to the flow region of a SIFT apparatus allowing the ions to be accelerated and hence the relative translational energy of the collisions between the ion and the neutral co-reactant to be systematically increased. This method called the selected ion flow drift tube (SIFDT or SIDF) allows reaction rate coefficients to be studied as a function of the reactant collision energy up to energies equivalent to $1800 \mathrm{~K}$ (Viggiano 2006). Because the applied field does not affect the internal energies of the ions, comparison of the rate coefficients under equilibrated high temperature conditions and those measured in SIFDT experiments allows conclusions to be reached about the effect of internal energy on the rate coefficients for ion-neutral reactions.

- Third was the development of the CRESU (Cinetique de Reactions Ecoulement Supersonique Uniforme, or reaction kinetics in uniform supersonic flows) technique by Rowe and his colleagues. Expansion of gas through specially designed convergent-divergent Laval nozzles generated gas flows with temperatures as low as $20 \mathrm{~K}$ (Rowe et al. 1984), a limit which was further lowered to $8 \mathrm{~K}$ by pre-cooling the gas using liquid $\mathrm{N}_{2}$ (Rowe et al. 1985).

For many - but not all - reactions between ions and neutral species, there is no activation barrier to inhibit reaction. Rather, the rate coefficient is controlled by the ability of the long-range attraction between the reactants to bring them into close contact. The simplest treatment of this capture process is appropriate when the interaction arises between the charge on the ion and the induced dipole on the neutral molecule. If the polarizability $(\alpha)$ of the molecule is independent of its orientation and the ion carries a single electronic charge $(e)$, then a simple treatment, generally referred to as the Langevin model, leads to the following expression for the rate coefficient for reaction between two species with a collisional reduced mass of $\mu$ :

$$
k_{L}=2 \pi e(\alpha / \mu)^{1 / 2}
$$

If cgs units are used for the quantities on the right-hand-side of this equation, $k_{L}$ is given in $\mathrm{cm}^{3} \mathrm{~s}^{-1}$ and has a typical value of $c a \cdot 10^{-9} \mathrm{~cm}^{3} \mathrm{~s}^{-1}$.

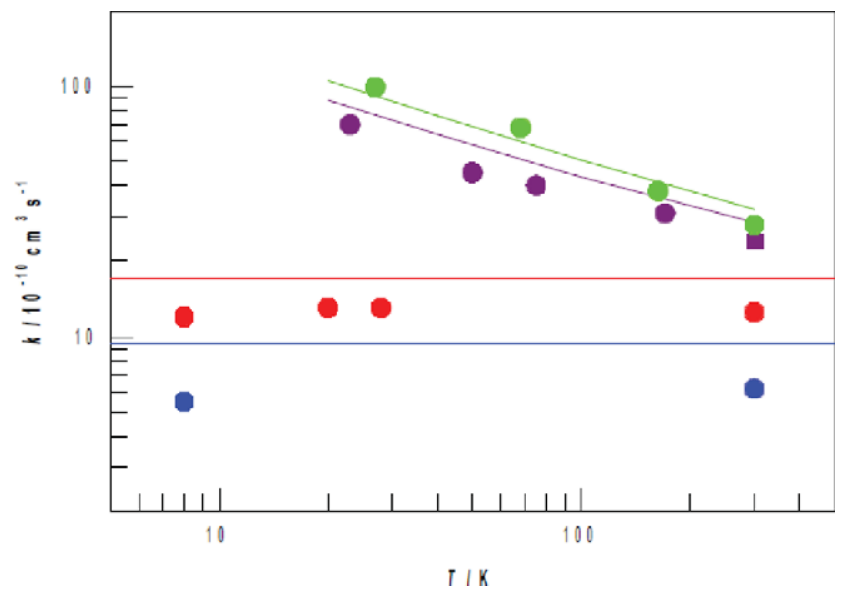

Figure 1. Example of rate coefficients for ion-neutral reactions. The symbols show experimental results for $\mathrm{N}^{+}+\mathrm{H}_{2} \mathrm{O}$ (green circles), $\mathrm{N}^{+}+\mathrm{NH}_{3}$ (purple circles and squares), $\mathrm{He}^{+}+\mathrm{N}_{2}$ (red circles) and $\mathrm{N}^{+}+\mathrm{O}_{2}$ (blue circles). The lines are theoretical fits according to the equations in the text. The sources of the experimental data are given in Smith (2011). 
Table 3. Methods used to study the kinetics of neutral-neutral reactions with the ranges of temeperatures over which experiments have been performed

\begin{tabular}{|c|c|c|}
\hline |Method & | Range of $T$ and $p$ & Reference \\
\hline DF - discharge-flow & \multicolumn{2}{|c|}{$\begin{array}{l}\text { typically: } c a .200-600 \mathrm{~K} \mid \mathrm{http}: / / \text { iupac-kinetic.ch.cam.ac.uk/ } \\
\text { up to } c a .1 \text { bar in the } \\
\text { turbulent flow reactor }\end{array}$} \\
\hline$\left|\begin{array}{l}\text { HTFFR - high temperature } \\
\text { fast flow reactor }\end{array}\right|$ & up to $1320 \mathrm{~K}$ & Cosic \& Fontijn (2000) \\
\hline $\mid \begin{array}{l}\mathbf{P L P} \text { - pulsed laser } \\
\text { photolysis }\end{array}$ & \multicolumn{2}{|c|}{\begin{tabular}{|c|c} 
typically: $c a .200-600 \mathrm{~K}$ & http://iupac-kinetic.ch.cam.ac.uk/ \\
down to $80 \mathrm{~K}$ & Fulle et al. (1996) \\
up to $c a .700 \mathrm{bar}$ &
\end{tabular}} \\
\hline $\begin{array}{l}\text { HTPR - high temperature } \\
\text { photolysis reactor }\end{array}$ & up to $1430 \mathrm{~K}$ & Fontijn et al. (2006) \\
\hline $\begin{array}{l}\text { PLP and CRESU } \\
\text { apparatus }\end{array}$ & $13-300$ & Sims et al. (1994), Smith (2006) \\
\hline
\end{tabular}

When the neutral reactant possesses an electric dipole moment $\left(\mu_{D}\right)$, in addition to the (assumed) isotropic attraction between the charge on the ion and dipole induced in the molecule, there is an anisotropic force between the ion and the molecular dipole. There have been a number of theoretical treatments of this situation, all of which are again based on the assumption that reaction will inevitably follow 'capture'. Wakelam et al. (2010a) recommend that the ratio of the rate coefficient for such a reaction $\left(k_{D}\right)$ to the Langevin value can be estimated in terms of a parameter $x$, defined by:

$$
x=\mu_{D} /\left(2 \alpha k_{B} T\right)^{1 / 2}
$$

In terms of this parameter, rate coefficients are given by:

$$
k_{D} / k_{L}=0.4767 x+0.620 \text { if } x \geqslant 2 \text { and }=\left[(x+0.5090)^{2} / 10.526\right]+0.9754 \text { if } x<2
$$

Fig.1 shows rate coefficients obtained at low temperatures $(\mathrm{T} \leqslant 300 \mathrm{~K})$ for reactions between atomic cations and two non-polar and two polar molecular reactants. They fit the formulae given above quite well - in particular, showing that the values of $k(T)$ are independent of temperature in the case of non-polar reactants but show a negative $T$-dependence in the reactions with polar molecules. It is interesting to note that the Langevin formula, Eq. 2.1, and its extension, represented by Eqs. 2.2 and 2.3, match the experimental results rather well, despite the fact that these reactions occur by charge exchange (that is, transfer of an electron) which does not obviously require a 'close collision'.

\section{Neutral-Neutral Reactions}

There is a large kinetic data base for neutral-neutral chemical reactions, mainly obtained for the purposes of modelling atmospheric chemistry (see http://iupac-kinetic.ch.cam.ac.uk/ and http://jpldataeval.jpl.nasa.gov/). For higher temperatures, kinetic data relevant to combustion systems have been evaluated by Baulch et al. (2005). Most of the kinetic data for the lower range of temperatures have been obtained through the use of two experimental techniques: discharge-flow methods and pulsed laser photolysis (Pilling \& Seakins 1995). In Table 1, I summarise the temperature ranges over which these methods have been employed to provide rate coefficients for neutral-neutral reactions. 
Of the 159 species identified in the ISM by July 2010 (Wakelam et al. 2010a), 136 are electrically neutral and most of these are potentially reactive as they are either free radicals, which have unpaired electrons or empty, low-lying, molecular orbitals, or unsaturated molecules, which contain one or more double or triple bonds. Clearly, this implies that neutral-neutral reactions can be important - even at very low temperatures, if the value of $\gamma$ in Eq.1.3 is close to zero.

The rate coefficients for reactions between radicals and saturated molecules typically, but not always, exhibit a positive dependence on temperature; that is, $k(T)$ increases with $T$ due to the presence of a barrier on the potential energy path leading from reactants to products. Two good examples of this behavior are provided by the reactions of the radicals $\mathrm{CN}$ and $\mathrm{C}_{2} \mathrm{H}$ with $\mathrm{H}_{2}$ :

$$
\mathrm{CN}+\mathrm{H}_{2} \rightarrow \mathrm{HCN}+\mathrm{H} \quad \text { and } \quad \mathrm{C}_{2} \mathrm{H}+\mathrm{H}_{2} \rightarrow \mathrm{C}_{2} \mathrm{H}_{2}+\mathrm{H}
$$

The extensive experiments on these reactions, from 300 to $3500 \mathrm{~K}$ in the case of (R2) and from 180 to $3000 \mathrm{~K}$ in the case of (R3), have been evaluated by Baulch et al. (2005), They express their recommendations for $k(T))$ in the form of Eq.1.3, with $\alpha=5.0 \times 10^{-13}$ $\mathrm{cm}^{3} \mathrm{~s}^{-1}, \beta=2.60$ and $\gamma=960 \mathrm{~K}$ for (R2), and $\alpha=1.95 \times 10^{-12} \mathrm{~cm}^{3} \mathrm{~s}^{-1}, \beta=2.32$ and $\gamma=444 \mathrm{~K}$ for (R3). Despite the significant positive values of $\gamma$, the reactions (R2) and (R3) could play a significant role in warmer regions of the ISM not least because the coreactant is the abundant molecule $\mathrm{H}_{2}$. The rate coefficients for reactions of free radicals with unsaturated molecules and for reactions between pairs of radicals show milder, and even negative, dependences on temperature, and consequently these reactions can be significant in cooler regions of the ISM.

Experiments on neutral-neutral reactions utilize the CRESU method to attain low temperatures (Sims et al. 1994; Smith 2006) and these experiments employ pulsed laser photolysis to generate atomic or molecular free radicals (such as $\mathrm{C}, \mathrm{Al}, \mathrm{Si}, \mathrm{B}, \mathrm{O}, \mathrm{CN}$, $\mathrm{OH}, \mathrm{CH}, \mathrm{C}_{2} \mathrm{H}, \mathrm{C}_{2}, \mathrm{C}_{4} \mathrm{H}$ ) in the presence of neutral co-reactants (especially, saturated and unsaturated hydrocarbons such as $\mathrm{CH}_{4}, \mathrm{C}_{2} \mathrm{H}_{4}, \mathrm{C}_{2} \mathrm{H}_{2}$ ). Generally, the rate coefficients for those reactions that are fast enough to be measured in CRESU experiments increase as the temperature is lowered - but the form of this variation is different for different reactions. Smith et al. (2006) have proposed two semi-empirical criteria that can be used to predict whether a reaction between a radical and an unsaturated molecule will be rapid (i.e., $k(10 \mathrm{~K}) \geqslant 10^{-10} \mathrm{~cm}^{-3} \mathrm{~s}^{-1}$ ) at the lowest temperatures found in interstellar clouds: (a) if the $\left(k(298 \mathrm{~K})>c a .5 \times 10^{-12} \mathrm{~cm}^{-3} \mathrm{~s}^{-1}\right)$, and (b) if the difference between the ionization energy (IE) of the molecule and electron affinity (EA) of the radical is $<c a .9 \mathrm{eV}$. These criteria have been supported by measurements on the reaction of oxygen atoms with a range of alkenes (Sabbah et al. 2007). Reactions between pairs of free radicals are likely to proceed over potential energy surfaces that exhibit no barrier to reaction: hence $\gamma$ in Eq.1.1 is likely to be zero. However, reactions between radicals are very difficult to examine in CRESU experiments and only the reaction $\mathrm{O}\left({ }^{3} \mathrm{P}\right)+\mathrm{OH}$ $\rightarrow \mathrm{O}_{2}+\mathrm{H}$ has been studied up to the present time (Carty et al. 2006).

A second problem in respect of neutral-neutral reactions, not only at low temperatures, is the measurement of product yields or branching ratios (Seakins 2007). Progress in this area has been made using infrared absorption techniques to determine the product yields relative to reactant loss or by comparing the relative yields of different products (Taatjes \& Hershberger 2001). Another technique, useful for a number of reactions of potential astrochemical importance, is to measure the relative $\mathrm{H}$-atom yields from several related reactions, either in discharge-flow (Bergeat \& Loison 2001) or pulsed laser photolysis 


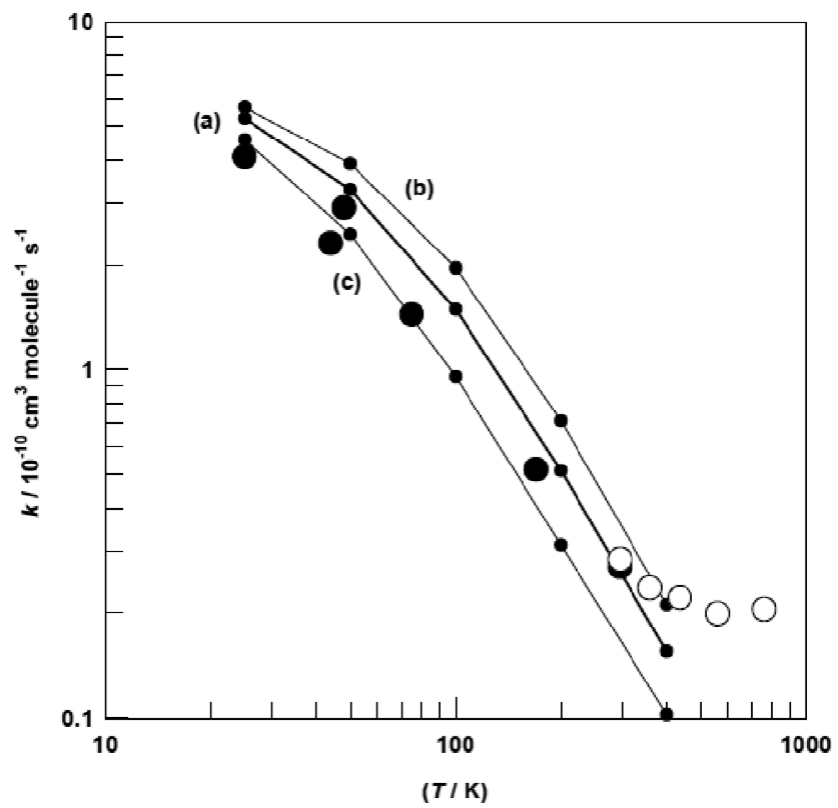

Figure 2. Comparison of experimental rate constants - filled circles (Sims et al. 1994) and open circles (Sims \& Smith 1988) - with theoretical values of the rate constants (Talbi \& Smith 2009): (a) with the zero-point level of the inner transition state $10.9 \mathrm{~kJ} \mathrm{~mol}^{-1}$ below the energy of the separated reactants; (b) with this energy difference increased to $13.4 \mathrm{~kJ} \mathrm{~mol}^{-1}$; and (c) with this energy difference lowered to $8.4 \mathrm{~kJ} \mathrm{~mol}^{-1}$.

experiments (Gannon et al. 2007). The relative yields can be converted to absolute yields if one of the reactions is known to generate $\mathrm{H}$-atoms in unit yield.

Finally, it should be pointed out that ab initio quantum chemical calculations can be very useful. To illustrate this point, and to show how calculations on a chosen reaction can provide detailed information, I refer to the reactions between CN radicals and $\mathrm{NH}_{3}$ molecules, which was one of the first two neutral-neutral reactions whose kinetics were studied in CRESU experiments (Sims et al. 1994). Between 295 and $25 \mathrm{~K}$, its rate coefficient increased markedly, the results being fitted to the expression: $k(T)=$ $(2.77 \pm 0.67) \times 10^{-11}(T / 298)^{-1.14 \pm 0.15} \mathrm{~cm}^{-3} \mathrm{~s}^{-1}$. In the experiments the rate of loss of CN radicals in the presence of known concentrations of $\mathrm{NH}_{3}$ was measured, so no information was obtained about the products and two sets of products are energetically possible:

$$
\begin{aligned}
& \mathrm{CN}+\mathrm{NH}_{3} \rightarrow \mathrm{HCN}+\mathrm{NH} 2 \text { for which } \Delta H_{298}=-78.9 \pm 0.8 \mathrm{~kJ} \mathrm{~mol}-1 \\
& \text { and } \mathrm{CN}+\mathrm{NH}_{3} \rightarrow \mathrm{H}_{2} \mathrm{NCN}+\mathrm{H} \text { for which } \Delta H_{298}=-38 \pm 10 \mathrm{~kJ} \mathrm{~mol}^{-1}
\end{aligned}
$$

Quantum chemical calculations (Talbi \& Smith 2009) demonstrated that there is no low energy path leading to $\mathrm{H}_{2} \mathrm{NCN}+\mathrm{H}$. These calculations further showed that the lowest energy path, leading to $\mathrm{HCN}+\mathrm{NH}_{2}$ passes initially through a potential well, 39.3 $\mathrm{kJ} \mathrm{mol}^{-1}(\equiv 4730 \mathrm{~K})$ below the energy of the separated reactants, and subsequently over a 'submerged barrier', with a crest $10.9 \mathrm{~kJ} \mathrm{~mol}^{-1}(1310 \mathrm{~K})$ below the energy of the reactants, which serves as an 'inner transition state' (Georgievskii \& Klippenstein 2007; Sabbah et al. 2007). The dynamics of reaction (R4a) were investigated (Talbi and Smith 2009) using the two transition state model of Georgievskii \& Klippenstein (2007). As Fig.2 shows the rate constants calculated for temperatures between 25 and 
$200 \mathrm{~K}$ are in excellent agreement with the experimental values. The conclusion that the reaction between $\mathrm{CN}$ and $\mathrm{NH}_{3}$ occurs exclusively by channel (R4a) has been confirmed in experiments in which the $\mathrm{H}$-atom yield from (R2) was compared with that from $\mathrm{CN}$ $+\mathrm{C}_{2} \mathrm{H}_{2}$ (Blitz et al. 2009). The latter reaction proceeds $100 \%$ to $\mathrm{HC}_{2} \mathrm{CN}+\mathrm{H}$ but no significant $\mathrm{H}$-atom signal was obtained from $\mathrm{CN}+\mathrm{NH}_{3}$. The example just cited demonstrates what can be achieved from combined theoretical and experimental studies on specific reactions. More generally, long-range transition state theory (Georgievskii \& Klippenstein, 2005) can be used to estimate upper limits to the rate coefficients for reactions where no barrier or inner transition state is likely to reduce the rate of formation of any intermediate complex. In applying this theory to radical-radical reactions, it may be necessary to multiply the result by a factor that allows for the fact that several potential energy surfaces correlate with the separated reactants (Wakelam et al. 2010a).

\section{Rate coefficients in chemical models}

Chemical modeling of regions of the ISM has a long history. Rate coefficients for the processes summarized in Table 1 are a major part of the input data for such models. The need for chemical databases became clear in the 1980s (Millar et al. 1991) and two such databases have now been available on the internet for some time (http: //www . ufda.net/ and http://physics.ohio-state.edu/ eric/research.html). They contain between 400 and 500 species and 4,000 and 5,000 reactions.

A third database, named KIDA (Kinetic Database for Astrochemistry) has recently been developed (http://kida.obs.u-bordeaux1.fr/). It incorporates two innovations: (i) outsiders can make recommendations that will be incorporated into the database after examination by a KIDA 'expert', and (ii) for each key reaction, the entry includes a data sheet which gives reasons for the recommended values of the rate coefficient and its uncertainty.

As well as comparing predicted molecular abundances with those observed, chemical models can be used to identify those reactions in the model which are key in predicting the abundances of particular species (Wakelam 2010a). This can encourage experimentalists and theoreticians to obtain new or improved data for these reactions. The inclusion of uncertainties in the recommended rate coefficients for reactions in the KIDA database is also important since they can be used to estimate the uncertainties in predicted abundances and hence make it possible to examine whether differences between observed and predicted molecular abundances are significant (Wakelam et al. 2010a, Wakelam et al. 2010b)

\section{Concluding remarks}

The limitations of time (in my talk at the Symposium) and space (for this article) mean that this short review has been highly selective. Amongst the topics that I have mentioned, it seems fair to conclude that the rate coefficients for most cation-neutral reactions are relatively well-known. The data base for anion-neutral reactions is smaller but rapidly expanding. Knowledge of the rate coefficients for neutral-neutral reactions has improved rapidly in recent years and the combination of quantum chemistry and rate theories is making the calculation of those for reactions where measurement is problematic much more certain. One experimental development, which should reduce the uncertainties in rate coefficients at the temperatures prevalent in the cold cores of dense interstellar clouds $(c a .10 \mathrm{~K})$, is the extension of CRESU measurements to lower temperatures, which 
is anticipated through the deployment of a pulsed version of the CRESU apparatus (Canosa et al. 2008).

I have briefly mentioned radiative association in connection with reactions (R1a) and (R1b). The ability to measure rate coefficients for these processes rests upon the facts that (i) ions can be trapped for "many minutes or even hours" (Gerlich 1995), and (ii) the $\mathrm{H}_{2}$ will remain in the gas-phase at sufficient concentration even when the trap is cooled to $c a .10 \mathrm{~K}$. Rate coefficients for other ion-neutral radiative processes must be inferred from measurements on the three-body association process and estimates of the rate of radiative stabilization. No experiments on radical-neutral radiative associations have been reported. Model calculations (Wakelam et al. 2010a) suggest that the reaction

$$
\mathrm{C}+\mathrm{H}_{2} \rightarrow \mathrm{CH}_{2}+h \nu
$$

is important in the cold cores of dense clouds. Determining its rate coefficient presents a formidable challenge to both experiment and theory.

Finally, I note that I have not mentioned several of the processes listed in Table1. Details of experimental measurements can be found in a longer review published elsewhere (Smith 2011). Dissociative recombination processes figure prominently in chemical models. Their rate coefficients have been determined in FALP (flowing afterglow Langmuir probe) experiments (Adams \& Smith 1988) and in experiments employing storage rings. The latter experiments (Geppert and Larsson 2008) have two advantages: (i) they allow time for any internal excitation of the reactant ions to cool before the neutral is introduced; (ii) they provide information about the neutral products of the process. One important instance of the latter type of measurements is the establishment of the branching ratios in the dissociative recombination of $\mathrm{H}_{3} \mathrm{O}^{+}$with electrons (Jensen et al. 2000).

\section{References}

Adams, N. G. \& Smith, D. 1976, Int. J. Mass spectrom. Ion Proc., 21, 349

Adams, N. G. \& Smith, D. 1988, in Rate Coefficients for Astrochemistry, T.J. Millar and D.A. Williams (Ed.) (Kluer, Dordrecht) p.173

Anicich, V. G. 1993a, ApJS, 84, 215

Anicich, V. G. 1993b, Phys. Chem. Ref. Data, 22, 1469

Baulch, D. L., Bowman, C. T., Cobos, C. J., Cox, R. A., Just, Th., et al., 2005, J. Phys. Chem. Ref. Data, 34, 757

Bergeat, A., \& Loison, J. C., 2001, Phys. Chem. Chem. Phys., 3, 2038

Blitz, M. A., Seakins, P. W., \& Smith, I. W. M., 2009, Phy. Chem. Chem. Phys., 11, 10824

Bohringer, H., \& Arnold, F., 1986, J. Chem. Phys., 48, 1459

Canosa, A., Goulay, F., Sims, I. R., \& Rowe, B. R., 2008, Low Temperatures and Cold Molecules, I.W.M. Smith (Ed.) (Imperial College press, London) p.55

Carty, D., Goddard, A., Köhler, S. P. K., Sims, I. R., \& Smith, I. W. M., 2006, J. Phys. Chem. A, 110,3101

Cosic, B., \& Fontjin, A., 2000, J. Phys. Chem. A, 104, 5517

Dunn, G. H., 1995, Phys. Scr., T59, 249

Durkin, D. B., Fehsenfeld, F. C., Schmeltekoff, A. L., \& Ferguson, E. E., 1968, J. Chem. Phys., 49,1365

Ferguson, E. E., Bohme, D. K., Fehsenfeld, F. C., \& Durkin, D. B., 1969, J. Chem. Phys., 50, 5039

Fontijn, A., Shamsuddin, S. M., Anderson, W. R., \& Marshall, P., 2006, Combust. Flame., 145, 543

Fulle, D., Hamann, H. F., Hippler, H., \& Troe, J., 1996, J. Chem. Phys., 105, 963 
Gannon, K. L., Glowacki, D. R., Blitz, M. A., Hughes, K. J., Pilling, M. J., \& Seakins, P. W., 2007, J. Phys. Chem. A., 111, 6676

Georgievskii, Y., \& Klippenstein, S. J., 2005, J. Chem. Phys., 122, 194103

Georgievskii, Y., \& Klippenstein, S. J., 2007, J. Phys. Chem. A., 111, 3802

Gerlich, D., 1995, Phys. Scr, T59, 256

Gerlich, D., 2008, Low Temperatures and Cold Molecules, I.W.M. Smith (Ed.) (Imperial College press, London) p. 121

Herbst, E., \& Klemperer, W., 1973, ApJ, 185, 505

Herbst, E., Smith, D., Adams, N. G., \& DeFrees, D. J., 1987, ApJ, 312, 351

Jensen, M. J., Bilodeau, R. C., Safvan, C. P., Seirsen, K., Andersen, L. H., Pedersen, H. B., \& Heber, O., 2000, ApJ, 543, 764

McIntosh, B. J., Adams, N. G., \& Smith, D., 1988, Chem. Phys. Lett., 148, 143

Millar, T. J., Rawlings, J. M. C., Bennett, A., \& Brown, P. D., Charnley,S. B., 1991, A\&A Supplt., 87, 585

Pilling, M. J., \& Seakins, P. W., 1995, Reaction Kinetics (New York, Oxford University Press)

Rowe, B. R., Dupeyrat G., Marquette, J. B., \& Gaucherel, P., 1984, J. Chem. Phys., 80, 4915

Rowe, B. R., Marquette, J. B., Dupeyrat G., \& Ferguson, E. E., 1985, Chem. Phys. Lett., 113, 403

Sabbah, H., Biennier, L., Sims, I. R., Georgievskii, Y., Klippenstein, S. J., \& Smith, I. W. M., 2007, Science, 317, 102

Seakins, P. W., 2007, Ann. Rep. Prog. Chem. Sect. C, 103, 173

Sims, I. R., \& Smith, I. W. M., 1988, J. Chem. Soc. Farad., 84527

Sims, I. R., Queffelec, J. L., Defrance, A., Rebrion-Rowe, C., Travers, D., Bocherel, P., Rowe, B. R., \& Smith, I. W. M., 1994, J. Chem. Phys., 100, 4229

Smith, I. W. M., 1988, in Rate Coefficients for Astrochemistry, T. J. Millar and D. A. Williams (Ed.) (Kluer, Dordrecht) p. 103

Smith, I. W. M., 1997, in Molecules in Astrophysics: Probes and Processeses, IAU Symposium 178, E.F. van Dishoeck (Ed.) p. 253

Smith, I. W. M., 2006, Angew. Chem. Int. Ed., 45, 2842

Smith I. W. M., Sage, A. M., Donahue, N. M., Herbst, E., \& Quan, D., 2006, Faraday Discuss., 133, 137

Smith, I. W. M., 2011, ARAA, to be published in September 2011.

Snow, T. P., \& Bierbaum, V. M., 2008, Ann. Rev. Anal. Chem., 1, 229

Taatjes, C. A., \& Hershberger, J. F., 2001, Ann. Rev. Phys. Chem., 52, 41

Talbi, D., \& Smith, I. W. M., 2009, Phys. Chem. Chem. Phys., 11, 8477

Wakelam, V., Smith, I. W. M., Herbst, E., Troe, J., Geppert, W., Linnnartz, H., Öberg, K., Roueff, E., Agundez, M., Pernot, P., et al., 2010a, Space Science Reviews, 156, 13

Wakelam, V., Herbst, E., Le Bourlot, J., Hersant, F., Selsis, F., \& Guilloteau, S., 2010b, A\&A, 156,13

Viggiano, A. A., 2006, Phys. Chem. Chem. Phys., 8, 2557

\section{Discussion}

L. Decin: You have shortly touched upon the field of ab-initio calculations/ quantum chemistry. Where do you expect to see the largest progress in next few years when combining laboratory experiments and quantum chemistry?

I. Smith: I believe that quantum chemical calculations will play an increasing role in identifying the reation products a) where multiple channels are energetically accesible, and b) where the minimum energy paths exhibit multiple transition states.

X. LI: The differences of rate constants between different modeling methods are apparent, especially at lower temperatures. Could you give some possible reasons of that? Thanks. 
I. Sмiтh: I believe that some of these differences may arise when some calculations do not correctly include the long-range interactions between the reactants. This is done in the transition state methods described later in Dr. Klippenstein's lecture.

E. Herbst: i) To what temperature do shock tubes provide rate constants? ii) Are internal degrees of freedom excited thermally

I. Sмiтн: i) I am not sure of the high temperature record but I know that the reaction $\mathrm{CN}+\mathrm{H}_{2}$ has been studied to $3000 \mathrm{~K}$ and $\mathrm{C}_{2} \mathrm{H}+\mathrm{H}_{2}$ has been studied to $3500 \mathrm{~K}$. ii) Rotational state distributions will be rapidly thermalised. Vibrational degrees of freedom can be more problematic - indeed shock tube methods are frequently employed to study vibrational relaxation at high temperatures.

M. Agundez: Concerning state-to-state chemical kinetics, i.e. measuring the rate constant of a reaction with one of the reactants in a given rotational, vibrational or electronic state, how feasible and trustable would be such measurements?

I. Sмітн: There is information on reaction rates from vibrational and electronic states for a few systems. It is more difficult to obtain rotationally selected rate coefficients since rotational relaxation is rapid with essentially all collision partners. 